Monográfico / Monographic

\title{
El malestar de la descivilización: creatividad como principio de realidad
}

\author{
The discontent of the decivilization: creativity as reality principle
}

\author{
Celso Sánchez Capdequi \\ I-Communitas: Institut for Advanced Social Research, Universidad Pública de Navarra, España. \\ celso.sanchez@unavarra.es
}

Recibido / Received: 19/04/2020

Aceptado / Accepted: 28/06/2020

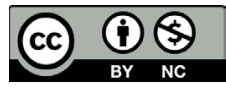

\section{RESUMEN}

El objetivo de este trabajo pretende insistir en las luces y las sombras de la creatividad en las sociedades tardomodernas. Hoy es el núcleo de la normalidad social. La creatividad es el nuevo principio de realidad. Su emergencia se explica a través de la victoria de Eros sobre Prometeo, como ya sugirió Marcuse contra Freud. Sin embargo, actualmente es el origen del nuevo malestar cultural. Si en la modernidad victoriana el dominio de Prometeo sobre Eros fue la causa del malestar, hoy Eros erosiona la necesidad de entendimiento social. En el nuevo malestar Eros es la personificación de una creatividad parcial que sólo busca emociones apoyada en el lenguaje algorítmico de las tecnologías digitales. En su dominio oculta otras posibilidades creativas como, por ejemplo, la deliberación racional o la experiencia utópica. El problema de descivilización aparece en el horizonte debido a la proliferación de identidades defensivas y la desaparición del otro en la vida social. Ante este desafío sólo una creatividad integral garantiza la posibilidad de producir afectos, pero también leyes, normas e identificaciones inclusivas.

Palabras clave: creatividad; civilización; mito; reflexión; articulación.

\section{ABSTRACT}

The aim of this contribution intends to insist on the lights and the shadows of the creativity in the latemodern societies.Today is the core of the social normality. The creativity is the new reality principle. Its emergency is explained across the victory of Eros over Prometheus, as already suggested Marcuse against Freud. Nevertheless, currently is the origin of the new cultural discontent. If in the victorian modernity the dominance of Prometheus over Eros was the source of the discontent, today Eros erodes the need for social understanding. In the new discontent Eros is the embodiment of a partial creativity that only search for emotions with the support of algorithmic language of the digital technologies. Its dominance hides others creative possibilities as, for example, the rational deliberation and the utopian experience. Thus, the problem of the decivilization appears in the horizon due to the spread of defensive identities and the decline of the other in the social life. In face of this challenge only a comprehensive creativity guarantees the possibility of produce affections, but also social laws, rules and inclusive identifications.

Keywords: creativity; civilization; myth; reflection; articulation. 


\section{INTRODUCCIÓN: LOS DOLOROSOS COSTES DE LA CIVILIZACIÓN}

Aunque su presencia no es una novedad de reciente factura, el malestar sigue instalado en la actualidad. El afianzamiento de la modernidad secular implica costes que la sociedad ha de asumir como parte inevitable de sus logros, y ello aunque el tono expresivo y estetizante de la época actual poco tenga que ver con la pulsión racionalizadora de sus inicios calvinistas. Freud es el promotor intelectual de ese diagnóstico pesimista en el que la frescura de los niveles primarios de la vida deseante es erosionada por las rigideces técnicas y morales de las sociedades postconvencionales. El curso mecánico de los acontecimientos predomina sobre cualquier asomo de contingencia que ponga en peligro las bases de la sociedad. El encendido vitalista de la ilusión y las decisiones sociales se apaga y se silencia ante los criterios objetivos de intervención en el mundo que rigen en la modernidad. En esa relación de tensión entre la ilusión y la realidad, el psicoanalista vienés detectó una sima profunda en la cultura moderna causada por un conflicto inexorable: la lucha irreconciliable entre Eros y Prometeo. Ambos arquetipos simbólicos lidian una vieja batalla sin final de la que la vida contemporánea es consciente por momentos. La modernidad victoriana vive con especial intensidad ese conflicto interminable porque su curso civilizatorio basado en el dominio racional del mundo triunfa a costa de someter a su mínima expresión las dimensiones deseantes y afirmativas de la vida arraigadas en la hondura humana. Se trata de garantizar y sostener la evolución cultural manteniendo a raya la espontaneidad expresiva de la vida cultural en todos sus apartados. Con sus atributos de celebración ceremonial, fusión empática y expansión creativa, Eros queda en manos de un Prometeo que juega a desactivar sus artes amatorias y embriagadoras. El resultado no es otro que el de una vida osificada bajo el dominio del orden y la taxonomía.

Sin embargo, esta descripción no hace justicia a la situación contemporánea. El diagnóstico del malestar perdura pero su naturaleza ha cambiado en sintonía con mutaciones sociales de enorme calado. Si bien Eros y Tánatos (entendido como el efecto desvitalizador de un Prometeo triunfante meramente especulativo) colisionan en una pugna incesante, la relación de fuerzas entre sendos contrincantes ha cambiado. Asimismo, la narrativa cultural y la trama de valores. El dispositivo de la creatividad instalado en el sustrato semántico de la tardomodernidad (Reckwitz, 2012) explica que, luego de un largo proceso histórico de cambio social, Eros haya adquirido ventaja sobre Prometeo. La expresividad como sustancia de la actual forma de vida coloniza los espacios más recónditos del escenario social. La otrora silenciada fuerza afirmativa de la vida se abre paso de manera abrupta ante unos frenos funcionales y especulativos que en los inicios de la modernidad reprimían esa vivencia oceánica de los actores sociales. Eros se ha rebelado y ha reconducido el curso de la evolución por derroteros desconocidos. Y ello hasta convertirse en algo inédito en la historia: el nuevo muñidor de la norma. Su fascinación creativa, transgresora y subversiva ofrece otros aromas y tonos: se encarga de cementar el orden y se olvida de trascenderlo. El elan erótico se traslada desde la periferia experimental de la bohemia de artistas al núcleo directriz de la agenda social ceñido al ideal de la innovación tecnológica. El perfil del artista sustituye al del especialista como patrón de comportamiento. Sin embargo, Eros ya no sorprende con sus irrupciones inesperadas desde la periferia inexplorada de la sociedad. Está en el centro. Más aún, es el centro de la agenda social. Se ha centrado cristalizando como pauta de orden. Se ha convertido en algo previsible a los ojos y a la mirada del público global. Ya sin el aura de su origen sacro del que habla la mitología griega (Calame, 2002), asienta su dominio al calor de un bullicio emocional estruendoso pero insensible a los efectos colaterales que deja a su paso. En el trance ha perdido el secreto y la extrañeza que turbaba la conciencia moral. Ahora es el embrión del sentido común.

El actual malestar de la cultura tiene que ver con esta metamorfosis axiológica. Luego del declive de la actitud hiperreguladora de la racionalidad formal, ahora la merma anímica 
surge de una versión prescriptiva y reguladora de Eros. Más que esperar sus apariciones siempre únicas y reveladoras, la sociedad se ve a sí misma obligada y abocada a la veneración forzosa y sistemática de este dios envanecido por una filigresía de creativos full time. Se trata de una divinidad que exige atención constante y sin descanso. Su presencia se rutiniza. Eros ya no requiere tiempos y espacios litúrgicos señalados en el calendario social como episodios cargados de sacralidad efervescente. En el presente ya no se le evoca y se le añora, más bien se le reclama y se le demanda a cada momento para obrar el milagro de la originalidad en todo acto individual. Vivimos en una relación amorosa cronificada y, por ende, previsible e in-trascendente. Predomina, por tanto, un constante y asfixiante estado de creatividad auspiciado por Eros. Pero, al mismo tiempo, no hay atisbo de alteridad subversiva porque Eros ya no procede del territorio de extrañeza que generaba en el pasado sospecha y temor. Hoy preside la morada ideal de la modernidad tardía que interpela a todos los individuos a formar parte de una comunidad inclusiva de creadores que sólo les reclama originalidad. El mundo, sus principios de organización social y el bienestar de sus pobladores quedan al margen de esta obsesión creativa. Sólo la sobreexcitación de los actores siente de cerca la pulsión tiránica del dios del amor.

Nunca como hoy se ha incidido tanto en las bondades de la creatividad, innovación, talento, inteligencia emocional y pensamiento lateral, $y$, al mismo tiempo, nunca como hoy el actor ha sentido tan de cerca una atmósfera de hipertrofia agencial en lo biográfico, lo político, lo ambiental, lo moral, etc. El eros creativo convive, paradójicamente, con un tiempo póstumo en el que la naturaleza, la vida, la civilización, Europa y, en estos momentos, la especie humana (amenazada por una pandemia), parecen vivir sus últimos episodios. El sustrato imaginario de este Eros creativo convierte a los actores, a todos los actores y no sólo a los artistas, en creadores capacitados para expresarse en sus actos y transformar sus relaciones con los otros y con el mundo en un episodio de reencuentro pleno con la complejidad del universo. Sin embargo, entre la narrativa de la creatividad y los hechos del mundo cunde el desánimo, cuando no la incomprensión y la extrañeza.

Eros ha arraigado bajo la forma de una razón solucionadora (Morozov, 2015) cargada de respuestas, pero ciega ante las demandas y los desafíos de la civilización. Las soluciones anteceden a las preguntas sin conocerlas ni debatirlas. Desde el exterior del debate social se impone a los individuos los temas y los asuntos a tratar. La preprogramación algorítmica de las herramientas virtuales traza los contornos de las preguntas y las preferencias. Eros imprime un modelo de vida sin dotarnos de las condiciones adecuadas para activarlo lúcidamente, para articular su potencial renovador a partir de la agenda de problemas planteados y discutidos en la deliberación política. Una vez fue la visita turbadora que agitaba las costuras culturales. En la actualidad se ha asentado en el centro de la sociedad sin noticia de aquellos episodios de otro entonces donde su aparición informaba de renacimientos radicales.

\section{EL MALESTAR DE LA CULTURA: EL DESENCANTAMIENTO DE EROS}

Hace un siglo la sociedad occidental presagiaba el peor de los escenarios. En ese lapso histórico Europa se fragmentaba en una relación de guerra de todos contra todos que iba a externalizarse a lo largo del planeta. Las potencias europeas rivalizaban por un mayor grado de dominio y control técnico del mundo. La locura se instaló en la conciencia de la sociedad y el límite moral de la convivencia y el entendimiento saltó por los aires dejando en evidencia la demencia de una racionalidad que se desentendió de los sentires y las sensibilidades de los actores sociales. El perfil del espíritu gregario y de la sociedad masificada evocaba la biografía hipertrofiada de un actor paralizado y sometido a un superyo moral invasor y violento. El catecismo profano de la técnica dinamitó el juicio moral de 
la conciencia. Su arraigo inconsciente no midió bien las consecuencias. 0, mejor dicho, al ser inconsciente, sólo una conciencia no absorbida por su magnetismo arrebatador podía haber hecho esa labor.

Freud (2018) traduce este debate en términos de un binomio que va a ocupar una parte central de su marco de reflexión: el principio de realidad y el principio de placer. Este último constituye el auténtico desafío de su indagación ya que él, como el conjunto de la sociedad de su tiempo, da por supuesto que la realidad no hay que definirla ni interpretarla; se define y se interpreta por sí misma. El principio del placer constituye el dominio inconsciente de la conciencia que $<$ corresponde a un funcionamiento primario del aparato anímico y que es inútil, y hasta peligroso en alto grado, para la autoafirmación del organismo frente a las dificultades del mundo exterior > (Freud, 2018, pp. 98-99). Por otra parte, <<bajo el influjo del instinto de conservación del yo queda sustituido el principio del placer por el principio de realidad, que, sin abandonar el propósito de una final consecución del placer, exige y logra el aplazamiento de la satisfacción y el renunciamiento a algunas de las posibilidades de alcanzarla, y nos fuerza a aceptar pacientemente el displacer durante el largo rodeo necesario para llegar al placer >> (Freud, 2018, p. 99). La realidad consiste en una organización de enorme complejidad evolutiva que aboca al yo a adaptarse a sus pujantes mecánicas de consolidación cultural. Se trata de la medida objetiva de las cosas llevada a la experiencia subjetiva. De esta suerte, $<<$ no se discute qué sea la realidad: se presupone su conocimiento. El hombre normal y el psiquiatra son su medida. La realidad es el medio físico y social de adaptación >> (Ricoeur, 1990, p. 226).

La exterioridad que rodea a la conciencia se concibe como lo real porque se trata del escenario que las fuerzas psíquicas deben tomar como referencia para pautar acertadamente su densidad instintiva y frenar sus tendencias atávicas. A ella debe ajustarse un cuerpo proteico y misterioso, el inconsciente, obligado adaptar sus dinámicas expansivas a la realidad bruta (y, por momentos, embrutecida). Por su parte, el principio de placer refiere a la dimensión profunda de una conciencia alucinatoria que, al estar asentada en las dimensiones primarias de la evolución, quiere estabilizar ese episodio de deseo incontrolado en el que no se tienen en cuenta las exigencias de complejidad evolutiva y en el que los obstáculos para la gratificación del placer parecen no existir. El principio del placer constituye la dimensión básica del inconsciente en su apartado económico: quiere consumar sus apetitos sin tensión ni resistencia. No le importa su objeto. Este cambia constantemente. Pero su límite y freno siempre está en los aledaños de una realidad ajena a la lógica simbólica de lo onírico. El principio de realidad cierra el paso a las ensoñaciones ancestrales que aspiran a consumarse inmediatamente en una realidad cuya consistencia objetiva resiste los afanes imaginarios de los individuos. La tensión entre estos y el desarrollo evolutivo y moral es una constante vivida trágicamente por la modernidad.

Sin embargo, esta ofrece un escenario en el que la evolución cultural, moral y técnica introduce novedades nada desdeñables. En especial, $<e l$ proceso de interdependencia creciente, la intensificación de la diferenciación de lasfuncionessocialesy, congruentemente, el establecimiento de vínculos cada vez más amplios, de unidades de integración cada vez mayores, de cuyo surgimiento y dinámica depende la vida del individuo, tanto si éste lo sabe como si no lo sabe >> (Elias, 1995, p. 330) dan forma a la civilización como garante de un mecanismo autónomo de la supervivencia ante las contingencias naturales. Los niveles evolutivos de la cultura han ido arrinconado aquellos residuos instintivos en los que el hombre habitaba la inmediatez y la espontaneidad alucinatoria. En estos planos primitivos de la evolución el intercambio social se reduce a actitudes reactivas. Sin embargo, la civilización obliga a ampliar el perímetro de la visión y a incluir a la pluralidad de grupos y sensibilidades sociales en las decisiones individuales y colectivas.

En los inicios de la modernidad este escenario fue investido de un carácter esencial basado en automatismos teleológicos que movían las cosas sin el concurso de las 
voluntades de los actores. La magia volvía al centro de la sociedad donde, en realidad, nunca había dejado de estar. Ahora su presencia activaba hierros, máquinas y cálculos con un providencialismo redentor que parecía tocado por lo extraordinario. La objetividad estaba cargada de la autoridad sagrada que antes correspondía a los seres legendarios de las viejas religiones. Con el psicoanálisis el sujeto se descubre atado a un principio instintivo que vive para la realización inmediata de un magma de deseos atávicos. Este sujeto atenazado por el piso inferior de los instintos en detrimento del piso superior del cogito sufre y padece al tener que reprimir ese principio del placer en un vida desencantada y ajustada al principio de realidad lubricado por el rigor del cálculo capitalista y por el credo doctrinal del cristianismo.

En el dominio del principio del placer sólo rige la actividad del instinto bajo la égida del pensamiento salvaje (Lévi-Strauss). En éste se promueven estados de intensidad afectiva a partir de imágenes vivaces que derivan las unas de las otras sin otro motivo que la similitud y la semejanza y en ausencia del conocimiento racional. Esas imágenes quieren ser satisfechas siempre y en todo momento. En su curso no cabe el principio de realidad. Más en concreto, es una compulsión a la repetición que cursa sin conciencia y sin reflexión sobre resistencias e impedimentos a la gratificación. Vive estabilizada en una secuencia cuyo origen se pierde en la noche de los tiempos. Sin embargo, el principio de realidad, surgido como control técnico del hombre sobre el mundo y como predominio del yo racional sobre sus dimensiones instintivas, bloquea y dificulta los apetitos de esta repetición deseante. Es más, según Freud, la civilización sólo puede reforzar sus logros si se paralizan las demandas instintivas de la repetición compulsiva que rigen en el principio del placer. El coste es el malestar de la cultura.

\section{EL REENCANTAMIENTO DE LA CULTURA: LA REVITALIZACIÓN DE EROS}

Tras la barbarie de mitad de siglo XX la figura de Eros se repiensa en el núcleo de la modernidad. Marcuse (1985) ofrece un diagnóstico cultural desde las premisas teóricas de la Escuela de Francfort en el que Eros y Prometeo establecen una nueva relación arquetípica y simbólica. La represión de los instintos en que descansa la evolución humana en el pensamiento de Freud recibe una represión adicional provocada por los criterios funcionales de la organización capitalista. La centralidad del trabajo, la relación de clases, la desigualdad, la plusvalía, la disciplina, junto a una sexualidad orientada a la reproducción de la especie, constituyen un escenario cultural en el que la figura de Eros se debilita más aún. Se trata de elementos al servicio de una minoría social que se reproduce como tal ahogando la expansión vitalista y lúdica para el conjunto de la sociedad. La ociosidad queda muy restringida a ciertas clases sociales, como bien sabía Veblen. Prometeo se reafirma en un episodio evolutivo en el que la represión adicional se corresponde con un interés de clase históricamente condicionado y con un universalismo etnocéntrico. Sin embargo, Prometeo podría perder su ce(n)tro simbólico de puro haber vencido en un curso evolutivo sustentado en fundamentos autorreproductivos. Estos garantizan la consistencia de la especie y, por ello, la represión instintiva es innecesaria y la experiencia lúdico-expansiva puede estar al alcance de cualquier individuo más allá de intereses particulares.

En este sentido, Marcuse reincide en la figura de Eros. Paradójicamente el triunfo de la civilización es el que justifica su retorno renovador. El principio de realidad capitalista basado en una eficacia económica adicional ya no añade nada a las bases estructurales de la civilización. Los cimientos sólidos de su edificación garantizan su permanencia definitiva. Ahora es el momento de Eros. Este simboliza valores e ideales basados en una libertad que convierten el principio del placer en un elemento compensatorio de revitalización. Ya no 
existen razones para impedir <<una reconciliación del principio de placer y del principio de realidad $\gg$ (Marcuse, 1985, p. 182). El principio de placer puede hacer descansar la vida social en la franja primaria de la evolución cultural en la que la participación, la ensoñación y la creatividad social siguen vivas. Eros supone el despertar de una imaginación anclada en la dimensión subterránea y ctónica de la conciencia que promueve el Gran Rechazo al statuo quo capitalista (Marcuse, 1985, p. 162). El capital crítico de los arquetipos culturales evocadores de gestos, ilusiones y utopías universales obliga al presente histórico a justificar y explicar sus elecciones históricas y sus efectos perversos. De puro habitar la superioridad de la civilización, se trata de retornar con garantías a los estratos inferiores de ésta y recuperar la oxigenación simbólica garante de la iniciativa y creatividad social absorbida por los sistemas funcionales en el curso civilizatorio.

Marcuse defiende el paso hacia adelante de la modernidad en el sentido de un tono civilizatorio menos represivo. La sustancia lúdica de la memoria imaginaria alienta un modelo de vida en el que Eros, junto a Orfeo y Narciso, cantan y danzan. Aquí Marcuse recupera la reflexión de Schiller (2018) en torno a las bondades del juego para una formalización recurrente y expansiva del orden social. De repente, las bases culturales de la civilización reactivan la expresividad silenciada. Más en concreto, el juego como criterio de una libertad que rompe con los criterios de eficacia y despierta la aparición de lo posible. Lo lúdico media entre la razón abstracta y el sentimiento individual, alienta una relación intersubjetiva en la que el carácter convencional de las reglas de juego se prolonga en el juego inmotivado con las reglas. Siguiendo a Schiller, Marcuse ve en el juego el desencadenante inmemorial que, sobre los cimientos consolidados de la evolución, anuncia un nuevo principio de realidad. El placer, la embriaguez, la ensoñación y la creatividad vuelven a participar directamente en episodios sociales en los que la expresividad anestesiada por el capitalismo abre la puerta a un modelo social integrador y solidario. Marcuse anticipa una tardomodernidad en la que el principio del placer tiende al centro de la sociedad abriendo la porosidad expresiva neutralizada por el rigor del cálculo capitalista y las formas sociales esperan a la creatividad para darse nuevos principios de organización. La estética será el rasgo de una civilización anclada en bases sólidas garantes del retorno de una voluntad de vivir siempre insatisfecha. Asimismo, las reflexiones de Maffesoli (2001) en torno al tribalismo trágico del actor posmoderno y de Bolstanski y Chiapello (2002) sobre la iniciativa artista de los actores en los procesos de producción capitalista coinciden en este giro estético de los discursos del presente (Alonso y Fernández Rodríguez, 2013). Eros se pone al mando de las operaciones del nuevo período cultural de la modernidad.

Llegados aquí, el malestar contemporáneo se explica desde otro marco de relaciones entre los principios simbólicos en conflicto. Surgen otros nexos de relación como algo específico de la tardomodernidad. La novedad contemporánea radica en una noción de creatividad que define el marco de los supuestos compartidos por el conjunto vario y diverso de la sociedad. A Eros ya no se le espera por sorpresa y como sorpresa. Reside en la sociedad de continuo manteniendo el orden y nutriéndole con el fomento de una creatividad expansiva ordinaria, secular y universal. Si en tiempos del capitalismo industrial Marcuse ve en la creatividad el símbolo de la negación y la contestación, en la actualidad Reckwitz detecta en ella la afirmación y la normalización de actual diseño social. La creatividad instalada en el centro neurálgico de la sociedad significa un giro radical de la situación anímica y cultural analizada por Freud. Su concurso supone que es el principio del placer el que, convalidado a-críticamente por el conjunto de la sociedad, deviene nuevo principio de realidad. Se trata de una realidad saturada de energía numinosa que la sociedad venera en sus formas y prácticas. No hay dudas acerca de su hegemonía. Define los contornos de lo normal. Las nociones básicas de lo bello, lo justo, lo bueno, y sus conceptos antagónicos, llevan en su seno el principio de creatividad. Este se define por dos rasgos (Reckwitz, 2012, pp. 10-19): por un lado, el perfil del artista que se expresa en sus obras y actos sustituye 
a la figura directriz del burócrata disciplinado y afín al rigor normativo imperante en los inicios de la modernidad; por otro, la búsqueda infatigable de la originalidad como rasgo que define una acción que normaliza la ruptura y la divergencia con lo canónico.

Ese nuevo principio de realidad entendido como principio de creatividad sólo quiere placer y disfrute. No en vano, $<<$ Eros, en su poder, anula precisamente toda capacidad de comprender y de decidir > (Calame, 2002, p. 24). El apetito insatisfecho se repite en él y desconoce o evita lo que impide tal realización. A él no se le opone la realidad. Es la realidad. El principio de realidad. Es decir, la pulsión de la repetición inscrita en el principio del placer creativo pasa a forjar un escenario en el que $<<$ la estabilización dinámica > de la modernidad (Rosa, 2019, pp. 14-15) promueve otro modelo de orden. Este ordena la existencia de cuerpos volcados hacia la originalidad a la que rinden culto ritual y cotidianamente. Viven para su logro y consecución bajo la evocación de un Eros que ha perdido la inocencia. Su figura antaño difusa e indescifrable hoy se ha convertido en un ídolo invasivo y feroz que obliga a una creatividad en la que, además del placer, los actores se juegan su reconocimiento social. Este ya no se ajusta a criterios como los de la heroicidad revolucionaria, el compromiso moral o la eficacia funcional. En nuestros días, el individuo diviniza a un Eros que imagina nuevos nexos de inspiración sin margen para integrar las exigencias de la alteridad social y bajo una inflamación egocéntrica sin límite.

De algún modo, Eros se ha desencantado. Gobierna las corrientes simbólicas de su tiempo orquestando un modelo de adaptación social en el que todo actor debe bordear la condición de un adelantado a su tiempo en contextos de aceleración y discontinuidad temporal y de héroes postheroicos (Bröckling, 2020). Se seculariza la noción de genio. Los actores viven en un compulsivo estado de enamoramiento creador. Eros ya no erotiza, más bien impone, obliga e intimida. Su otrora visita transgresora ya no es algo irrepetible y único. Se ha banalizado. Ya sin los tonos de lo extraordinario el acto creativo se instala en la cotidianidad y la moldea. Eros vela por la consolidación de ésta. Es el garante del nuevo principio de realidad. Por paradójico que parezca, sistematiza la creatividad como forma de vida. Su presencia social como principio de realidad implica varias cosas.

Una primera, la experiencia humana pierde la profundidad abismal y el misterio evocado por Eros. El actor se diluye en un revival creativo dirigido por una maquinaria algorítmica de los afectos y una preprogramación reductora de sus dotes renovadoras. Es más, anuncia un nuevo imperativo estético en el que la creatividad no es una elección deliberada sino una compulsión obsesiva (Reckwitz, 2012, p. 10). Eros se distancia de la ambivalencia de lo sagrado que incorporaba a sus apariciones ancestrales bajo formas como ménades, bacantes y sátiros. El tono secular de la época sintoniza con un Eros despojado de restos de extrañeza evocadores de un inframundo amenazante por carente de reglas. El amor y la muerte son el anverso y el reverso de Eros (Bataille, 1997, pp. 87-88). Sin embargo, su pulsión subversiva se petrifica a causa de un sistema ciego de operaciones algorítmicas. El ademán prescriptivo de Eros erosiona la radicalidad transgresora que el amor activaba en las liturgias orgiásticas y delirantes (Bataille, 1997, p. 93). El amor hoy es pornografía, pura visibilidad televisiva y televisada (Han, 2017, p. 59). Sus encantos mitológicos se han pervertido en puro acto corporal a los ojos del público global. El amor se ve, se observa, se visibiliza. Es parte nuclear del sentido común contemporáneo. Ya no evoca ni sugiere desde dominios extraños y desconocidos. Todo se conoce en él. Su misterio ya no atrae. Lo que convoca de Eros es la contaminación y el contagio corporal a través de imágenes accesibles por doquier en tiempo real.

Otra consecuencia de la creatividad como principio de realidad es la realidad misma. La normalización de lo sentimental como marco característico de la experiencia se traduce en modelos de percepción social volcados a la satisfacción inmediata y carentes de resistencias y frenos. El amasijo de pantallas catalizadoras de esa espontaneidad emocional 
facilita patrones de comportamiento en los que la verosimilitud de las cosas pasa a un segundo plano. A partir de ahora verdad es expresividad convulsa e histriónica surgida por agregación caótica de emociones y no por selección pautada de argumentos. La verdad se instala en un mundo plano y sin matices en el que todo se abre paso sin dar razones y pasar filtros. La verdad ya no es cognitiva y compartida, más bien pura experiencia de evitación en la que se pospone o se aparta cualquier atisbo de adversidad y discrepancia. Todo aquello que cuestiona o pide razones a la expresividad emocional es denostado y causa de indignación e ira. Se trata de un modelo de sociedad basado en una visión particularista que exige del mundo social un reconocimiento inmediato. El otro es siempre un correligionario o cómplice, nunca un espectador imparcial o escéptico. El principio de realidad acuñado por la creatividad ha devenido voluble, sospecha de lo universal y bordea expresiones de <<sentimentalismo tóxico >> (Dalrymple, 2017). El solapamiento de particularismos sin vínculos comunicativos entre ellos desemboca en una realidad de parte, parcial y particular no exigida por principios de obligado cumplimiento. Los vínculos con los otros se han diluido sin dejar terreno expedito para la transformación intersubjetiva del hecho social. Los grandes problemas de la humanidad, ya sean pandemias, guerras, crisis económicas, esperan mientras tanto una respuesta colegiada.

\section{EL ROSTRO Y EL RASTRO DEL MALESTAR: EL TRIUNFO DE EROS EN EL TIEMPO DEL SOLUCIONISMO TECNOLÓGICO}

La tardomodernidad creativa genera cadáveres en el camino. Eros se ha situado en el centro de la agenda social y se ocupa de sostener el edificio de la civilización estetizante. Se acabaron esos episodios de eterna juventud en los que revitalizaba las relaciones por su afinidad con el caos originario de una religiosidad fundante. En ese trance lo llevaba todo a un contacto iniciático que derivaba en conversión. Hoy su impulso trágico (Bataille, 1997, p. 87) se ha disuelto en una pulsión tiránica. Sus movimientos tienen más de procesos de osificación que de renovación, más de densidad histriónica que de revolución de arriba abajo. Eros, como el dios Yahvé, reclama fidelidad exclusiva y ordena que sólo veneremos sus atributos egocéntricos de ruptura y transgresión en ausencia de otros de tipo moral, solidario, hermenéutico, reflexivo, etc. Pero ya sin la contraprestación del valor universal de la salvación ultraterrena: sólo aspiramos a una salvación secular y terrenal efímera y cortoplacista.

Esta situación de entrega desinteresada a un Eros demandante más que donante genera malestar cultural. Para dar cuenta de éste, no son desdeñables otros diagnósticos ofrecidos en los últimos años por la investigación sociológica como, por ejemplo, los de los efectos colaterales de una modernización selectiva, la aceleración desbocada de la temporalidad tardomoderna, la guerra de civilizaciones, el neoliberalismo económico, entre otros. Sin embargo, el cetro hegemónico de Eros obliga a buscar la causa del malestar en otra dirección.

El malestar de la cultura tardomoderna, junto a todos estos elementos de diagnóstico, tiene más que ver con una suerte de disonancia creativa existente en forma de contradicción entre una inflación discursiva de la creatividad y su ausencia operativa en los dominios subjetivos e intersubjetivos de la vida social. Entre la sobreabundancia narrativa y la ausencia de cauces de acción se abre el abismo. El verbo no se hace carne. Ni la promesa tampoco realidad. El perfil del artista sigue siendo cosa de pocos. Ahí crece el malestar. Este ya no se expresa en términos de predominio funcional y erosión emocional, sino a partir de una primacía asfixiante de la afectividad estetizante. La creatividad cruza incontroladamente la enorme variedad de universos culturales de la sociedad, sin embargo, los actores viven con impotencia y desorientación su plasmación social. Desconocen la gestión lúcida y 
responsable de la misma. Se les escapa de las manos y no la incorporan como elemento básico de sus biografías. No ocurre en todos los sectores de la sociedad. Aunque surge como ideal al alcance del conjunto de actores del planeta, sólo una minoría elegida la representa con éxito y una mayoría la padece (Zafra, 2017). Como ocurre con frecuencia en la historia social, la creatividad queda representada unilateralmente por un grupo concreto. La clase creativa de la que habla Richard Florida constituye un sector de la sociedad que crece en el contexto de la sociedad del conocimiento en la que la hipercualificación cognitiva, el valor del cosmopolitismo y la búsqueda de originalidad constituyen sus rasgos más relevantes. Reckwitz (2019) la denomina la nueva clase media (p. 90 y ss.). No se trataría tanto de la desaparición de la clase media como de su dualización. La vieja clase media es reconocida por su adaptación a la función profesional, por la uniformidad rigurosa de sus actos, por la neutralidad afectiva y por la identificación con el centro de trabajo. La nueva clase media es más académica, dinámica, arriesgada, cosmopolita y atenta al autodesarrollo personal.

En principio, entre la sobreestimulación simbólica de la creatividad y su realización personal e inter-personal se anuncian sombras inesperadas que se interponen. La inmensa mayoría de la sociedad vive desde la distancia la apropiación hermenéutica de la creatividad en sus entornos locales y globales. La biografía se narra creativamente en la escuela, en la familia, en el trabajo, en el amor, en el deporte, pero esta narrativa no contempla, más bien, oculta, un sinfín de resistencias y obstáculos que alejan al actor de una orientación creativa en todos estos planos. Asimismo, la política y la cultura se dicen creativas, sin embargo el mecanismo de reproducción de la civilización de las redes globales parece inmune a cualquier propósito transnacional orientado a transformarlas. Estas se mueven sin pautas ni seguimientos convalidados por los actores sociales. En un plano como en el otro cunde la impotencia ante cursos de acción que se mueven con ritmos que silencian la inventiva social. El nervio hipersubjetivo de la creatividad desactiva su dimensión intersubjetiva. Junto a la creatividad, viejos fantasmas como la escasez, la injusticia, la violencia y la huida de la realidad, y otros más recientes como el retorno a lo local, el hiperactivismo estético, la tiranía de la imagen y el tiempo de la aceleración, dan cuerpo a un hecho social tornado en alienante. $Y$ todo ello a pesar de un glamour creativo formalmente democratizado, pero realmente inexistente.

Más en concreto, el malestar actual crece en un entorno cultural tecnológicamente saturado en el que los automatismos algorítmicos predefinen las respuestas sociales sin atender a la definición de los problemas por parte de los actores (Morozov, 2015, p. 24). Estos se desvinculan de aquellas, o, dicho de otro modo, las respuestas nada tienen que ver con los desafíos inmediatos de los actores. Estos enmudecen en el planteamiento de sus preguntas. Se quedan sin expresión y sin cauce operativo. El mecanismo de la respuesta precede al planteamiento de las cuestiones más urgentes de la sociedad. Morozov denomina a esta situación el solucionismo tecnológico (Morozov, 2015, pp. 19-35). Con esta expresión el autor quiere definir ese desajuste entre una creatividad preprogramada, que sólo sabe de respuestas, y una ausencia de protagonismo deliberativo de los actores despojados de atributos creativos en lo más propiamente innovador de la sociedad. Los problemas de la sociedad no son hechos per se, objetivos y neutrales. Se constituyen como tales al calor de la proyección semántica del colectivo.

En este caso, y de manera paradójica y perversa, la respuesta algorítmica responde pero no satisface porque su mecánica preprogramada desoye la creatividad política de la sociedad acerca de las preguntas sustantivas e inexpresadas que interpelan a los actores sociales. El tema de discusión y debate es fijado sin la intervención de la iniciativa de los hablantes. El mundo de los hechos va por un lado y la voluntad intersubjetiva por otro. La creatividad social se ausenta del horizonte de decisión política y se desplaza hacia el horizonte cruzado de innovación tecnológica y cultura estetizante. Los medios lustrosos de la tecnología y sus múltiples posibilidades de aplicación se convierten en el tema a 
debatir. Sus estructuras algorítmicas, robotizadas e inconexas en clave de tuits, memes, fakes, etc. erosionan cualquier atisbo de conversación porque en ellas no son posibles las conclusiones ni los balances. El mecanismo soterrado del algoritmo ha generado un mecanismo de acción que crea pero sin voluntad intersubjetiva, sin profundizar en el fondo existencial de los actores, dejándoles de lado. Estos intentan dar salida a esa creatividad, pero ésta ya le viene dada sin orientarla ni dirigirla: sin sentirse artífices creativos de los problemas y de las soluciones. Viven la creatividad de otro, de otros, de desconocidos que les dan respuesta sin haber sido preguntados por los actores. Viven una creatividad de prestado que nada tiene que ver con las urgencias y las ilusiones directrices de su cotidianidad.

Una vez más la acción cede su protagonismo a procesos anónimos que la alejan de la autonomía demandada por la sociedad moderna (Joas, 1992, p. 395 y ss.). En este contexto de expropiación creativa el malestar se abre paso porque los actores tienden a canalizar creativamente sus decisiones, pero sin vivir estos procesos de manera lúcida y responsable. Sin articularlos. Sin decidir ni dirigir el proceso de innovación creativa el hecho social se convierte en un extraño. Casi alienante. La proximidad connatural entre creatividad y responsabilidad se diluye. Los actores habitan un escenario que les define como artífices de sus contornos, pero sin contar con ellos en su proceso de gestación. Esa ausencia de responsabilidad en los procesos de cambio social explica una minoría de edad representada en tipos como los populismos políticos, los fundamentalismos religiosos y los esencialismos culturales, todos ellos ajenos a los efectos perversos que sus prácticas generan más allá de su perímetro de acción. Su mirada se limita a los escenarios en los que creen ser dueños y protagonistas de sus gestas. Se trata de identidades defensivas (Reckwitz, 2019) cuya mirada in-trascendente encarna un episodio de malestar crónico en el que las biografías humanas se encierran en lo más próximo ante desafíos globales despojados de autoría creativa y responsabilidad.

\section{EL MALESTAR DE LA DES-CIVILIZACIÓN}

La creatividad como nuevo principio de realidad estimula la plasmación cotidiana de lo sentimental. La expansión de los afectos no supone una excepción, sino la regla de comportamiento generalizado. Sin embargo, la creatividad difundida como norma cultural nos impulsa y nos lanza pero sin guía ni orientación, sin voluntad ni propósito. Todo se limita a la exhibición pornográfica e impúdica de Eros (Han, 2017, p. 59), carente de otra pretensión que la de agitar por la agitación misma sin parar mientes en las costuras de las instituciones sociales y en su carácter provisional. Esta dimensión no es problema. En una sociedad en la que quien piensa es el algoritmo la realidad se petrifica a salto de combinación preprogramada. Entre soluciones impuestas y problemas no planteados el único indicio de creatividad humana es una explosión torrencial de los afectos que, paradójicamente, cuanto más intensa se expresa menos se detiene en la mecánica subyacente que la activa. Esta trabaja en la sombra a modo de alquimia mágica que no deja espacio para la pauta deliberativa de los actores. Nunca se ha sabido menos de esa fuerza magmática de cambio social, el imaginario (Castoriadis, 1983; Cristiano, 2009), que en la época de la creatividad. Se crea sin propósito pero con respuesta algorítmica, se crea desde la expresividad pero sin narrativa, se añora más autonomía y responsabilidad pero sin saber cómo canalizarlas en ausencia de espacios de deliberación y autocorrección política.

Ese resto afectivo superviviente de lo humano en la selva algorítmica anuncia lo que Nachtwey (2017) denomina la descivilización de la cultura (pp. 130-142). Este investigador de inspiración francfortiana detecta la quiebra de las bases estructurales de la civilización 
como riesgo inmediato que se cierne sobre el tiempo actual. La suma de afectos y preprogramación virtual genera las condiciones de un debilitamiento de la civilización que tanto preocupó a Freud y a sus contemporáneos. El nuevo principio de realidad en el que el placer creativo se expresa por doquier, pero sin llegar a cuestionar los principios rectores de la sociedad recuerda los peores presagios de los inicios del siglo XX en los que Prometeo temía las ardides embriagadoras de Eros. Hoy éste define el trance cultural de la civilización, pero en ausencia total de pensamiento abstracto, trascendencia, teoría y compromiso para con lo universal. La modernidad ha entrado en una fase regresiva. Hoy la sociedad se sitúa ante la reedición de lo ya anunciado por Weber (1986) hace un siglo en términos del <<sacrificio del intelecto»> (p. 228). No es que éste se vea en peligro por las demandas desproporcionadas de los credos religiosos y de los profetas y místicos de la tardomodernidad, como sospechaba el propio Weber. Más bien, la sociedad contemporánea ha infravalorado en sus contextos de acción real y virtual la orientación deliberativa de la opinión pública. El fasto emocional alentado por Eros penaliza cualquier atisbo de reflexión analítica. El intelecto sencillamente no juega ningún papel en la configuración de las instituciones contemporáneas. La voluntad general se confunde con el agregado caótico de subjetividades superpuestas en las redes sociales sin filtros y sin consensos. La (des-)orientación de los procesos sociales queda en manos de una afectividad abrupta y desarticulada. Ya no es Dios ni sus fieles dogmatizados los responsables del sacrificio del intelecto, sino una mecánica impersonal con intereses desconocidos y ausentes del debate creativo de la sociedad. Lo que preprograma algorítmicamente queda fuera de la preprogramación, no es parte de sus contenidos.

Nachtwey explica este proceso como descivilización porque las notas básicas de la civilización se están erosionando. Esta amenaza se traduce en una sociedad sin propósito y sin medio y largo plazo en sus decisiones. La carga emocional y la volubilidad de sus dinámicas generan escenarios de corto alcance, de digestión inmediata, de esteticismo abrupto, de ausencia de comprensión y de deliberación colegiada. En ellos todo es extremo básicamente porque no hay centro, ni parece necesario. Se ha normalizado la tendencia centrífuga. Y, con ella, la extravagancia localista. No se va más allá, no se ve más allá, no se atiende a los (d)efectos trascendentes del hacer o no-hacer. Para los particularismos el perímetro local del mundo es el mundo mismo. Lo otro, sospecha y amenaza. La fugacidad con la que nacen las cosas no da pie más que a o conmigo o contra mí, sin las mediaciones de diagnósticos reflexivos que introducen tiempo largo para reconstruir lo fragmentario y acercar los extremos. Se trata de una vida sin balances cuyos actores parecen responder a cámaras, pantallas y programas virtuales que no les exigen elaboración narrativa. El resorte de la expresividad forzada quebranta la necesidad del logos, la acumulación de evidencias, los filtros hermenéuticos, los contrastes serenos y las conclusiones consensuadas. La civilización contemporánea renuncia a aquellos atributos de los que hablaba Elias (1995) tales como el autocontrol individual, la ampliación del campo mental, la renuncia a la satisfacción inmediata de las urgencias vitales y el pensamiento a largo plazo. Más en concreto, rehuye la idea de Talcott Parsons relativa a generalización de los valores como nota que hace reconocible a la modernidad.

De este modo, la civilización corre el riesgo de tornar en descivilizacion cuando se cierne sobre ésta el peligro de la afectividad imperativa y descoordinada. La compulsión a la repetición resurge bajo el modo de sentires que se expresan sin comprender(se). El largo plazo hoy es una pieza de museo. La universalidad concreta que reclama Joas (2017, p. 26) y la trascendencia de un mundo con resonancia que propone Rosa (2017) ofrecen claves para reconducir las bases de una civilización que no ha de degenerar en descivilización si aprende a reintegrar colegiadamente los fragmentos particularistas de su realidad. Esta tarea exige la convalidación de una teoría que, lejos de imponer y someter en nombre de la axialidad euro-occidentalidad, traduzca a un lenguaje neutral de común entendimiento los 
ideales y los mitos desperdigados por la cultura humana. Sin racionalidad crítica presente en las tradiciones axiales esto es sencillamente imposible. Como dice Assmann (2018), no es que el logos griego suponga la superioridad de un modelo humano sobre cualquier otro más afín con la mentalidad primitiva (Lévy-Bruhl). Más bien, Grecia, la cultura judía, la confuciana, la budista, etc., han aportado las fuentes clásicas del pensamiento, textos canónicos y Sumas teológicas y metafísicas en torno a las cuales el hombre se puso a meditar sobre su tránsito por el mundo y su acceso a la salvación extramundana. Esos interlocutores siguen dialogando con nosotros. Nos empujan a evaluar nuestras decisiones y sus efectos. Y nos ayudan a crear conjuntamente comprendiendo al otro a partir de los denominadores comunes a todas las culturas, civilizaciones y religiones axiales. Sobre estas bases debe crecer el episodio creativo de unos actores que narran problemas, bosquejan vías de explicación y consensuan soluciones compartidas.

\section{DISCUSIÓN Y CONCLUSIONES: LA ARTICULACIÓN DE EROS}

El malestar de la cultura se enquista una vez que la restitución de Eros en el centro simbólico del imaginario tardomoderno no aporta la plenitud anunciada en las biografías de todos sus feligreses. El imperio de Eros deja fracturas e hilos sueltos en la sociedad contemporánea. A su sombra se revitaliza la pulsión lúdica, pero sin contrapesos deliberativos y reflexivos. Los vastos espacios de comunicación social y de transmisión de experiencias se entregan a una cacofonía impúdica que sólo celebra el ruido. La civilización reduce su alcance a la expansión emocional sin habilitar espacios para definir la realidad y consensuar correcciones sobre el tejido institucional. La sombra de la descivilización se abre paso si, bajo la sola evocación a Eros, el acto social sazonado de hiperexpresividad oculta la enorme complejidad que implica. En el vigente imaginario de la creatividad, ésta muestra un perímetro de acción muy restringido. Ahí está la causa del actual malestar civilizatorio: la creatividad contemporánea remite a uno de los perímetros de la vida social, pero olvida otros planos constitutivos de la inventiva humana.

Los déficits de este contexto cultural tienen que ver con el hecho de que Eros estira su encanto en el marco de un antagonismo muy marcado entre instinto y razón. El triunfo de la expresividad estética supone la venganza del mundo onírico convertido en pauta de orden y en clara oposición a las otrora tendencias dominadoras de la racionalidad funcional. 0 instinto depurado de reflexividad teórica o razón pura despojada de impurezas atávicas. En este esquema cultural el cambio social sólo puede entenderse como la imposición de un ideal simbólico a partir de la desaparición, merma o eliminación de todo lo demás. Cuando Marcuse evoca las virtudes aglutinantes y solidarias de Eros y su vínculo arquetípico con Orfeo y Narciso, deja de lado o envía a la inoperancia a una razón que ya ha hecho su trabajo, o que, sin más, ya no debe importunar en el nuevo idilio entre el individuo y la sociedad. Este argumento supone un ejercicio de compensación que equilibra el ofrecido por Freud en términos de superioridad de la razón sobre el instinto. Pero olvida que el binomio instinto versus razón frena cualquier proceso de renovación lúcida y colegiada si oculta la dimensión habilitante y reveladora de la especulación. Sólo está puede poner voz y sentido a la profundidad onírica del inconsciente.

Así las cosas, se da una oposición muy marcada entre lo que sólo quiere y lo que sólo impide, lo que se expande y lo que restringe. Este es el binomio desde el que piensan Freud y Marcuse y, en general, las ciencias sociales desde su nacimiento. La reflexión de estos autores crece en el seno de este evolucionismo decimonónico en el que los niveles evolutivos se relacionan por exclusión. Y eso mismo se reproduce en la sociedad actual en la que el emotivismo histriónico ha excluido de sus dominios cualquier asomo de reflexión o especulación. Estas facultades teóricas son penalizadas en la actualidad porque 
trascienden los contornos emergentes de lo particular y expresan los viejos fantasmas del etnocentrismo, imperialismo, colonialismo, aún presentes en el imaginario de la sociedad. Pero esta pulsión excluyente olvida que la teoría no sólo resta y escinde, también suma y reintegra, no sólo dispone de virtudes restrictivas, también habilitantes. En este sentido, es un dato muy sugerente que en gran parte de las teorías sociales dedicadas a la creatividad, como son las de Castoriadis, Maffesoli, Durand, etc., la razón es una presencia extraña que no comparte nada con la sustancia onírica del inconsciente, a la que agrede y erosiona. Se trata de dos lógicas antagónicas que no saben la una de la otra porque se ha roto el vínculo evolutivo entre ellas.

Sin embargo, de las aportaciones científicas más recientes se desprende que entre el instinto y la razón hay muchos elementos evolutivos en juego que movilizan la acción social. Han pasado muchas cosas en este interregno evolutivo que siguen muy presentes en el sentido común contemporáneo. Siguiendo a autores como Donald (1991), Deacon (1997) y Tomasello (2003) nada de lo creado en la evolución cultural desaparece como capacidad de formalización cultural en cualquier presente histórico. El proceso de evolución no actúa por exclusión, sino por inclusión. Según Donald (1991), el instinto necesita representación ritual con la que la criatura humana introduce un primer intento de control corporal y dominio de la experiencia. Asimismo, este episodio ritual demanda la aparición de la narrativa mitológica para reforzar la secuencia de las cosas y organizar la conciencia y el pensamiento. Por último, el surgimiento de la teoría permite al hombre pensar y pensarse al concebirse como parte minúscula de una infinitud enigmática. En este sentido, el análisis cultural obliga a trascender los antagonismos. Se necesita algo más. Urge combinar más piezas culturales que siguen presentes en la actualidad y que la mirada particularista no acierta a integrar en sus relatos.

Se decía arriba que el hombre contemporáneo dispone de capacidad de respuesta más allá de las tendencias invasivas del algoritmo. Puede descubrir márgenes de creatividad subjetiva e inter-subjetiva desde el momento en que encuentra nexos de continuidad entre los estratos culturales que descansan en él. Aquí radica el embrión de una creatividad con-sentida vitalmente y dirigida argumentativamente. Una opción a explorar con la que hacer frente desde la investigación social más actual al malestar de la cultura auspiciado por Eros consiste en ampliar los recursos culturales de la especie que siguen vigentes en la actualidad desde tiempo inmemorial. En ella dialogan y comunican el trance místico, el rito, el mito y la teoría. Como dirían Schutz y Luckmann (1989), las pequeñas trascendencias (el conocimiento de la experiencia cotidiana), las trascendencias intermedias (el conocimiento del otro) y las grandes trascendencias (el misterio inefable) (pp. 99-130). Se trata de huir de cualquier intento de oponer antagónicamente mito y logos, pensamiento salvaje y razón pura. La creatividad necesita, por el contrario, impulso integrador que incluya todo episodio cultural de la especie, todo lo imaginado a lo largo de la evolución (Durand, 2005, p. 21). Para ser lúcidamente orientada necesita del reconocimiento pleno de la continuidad fecunda de los niveles evolutivos de la cultura humana. Ya en los años 70 del siglo pasado la noción creatividad integral propuesta por Maslow (1983, p. 198) abre una vía de reflexión en la que la simple oposición entre inspiración inconsciente y rigor técnico no basta. Es necesario, a su juicio, un nivel intermedio de creatividad que permita la traducción argumentativa de vivencias subjetivas en ideales intersubjetivos, del fondo desarticulado de los contenidos implícitos en relato articulado por medio de la racionalidad discursiva. Bellah secunda esta visión en la última parte de su obra incidiendo en un evolucionismo no evolucionista inspirado en la obra del psicólogo ya mencionado Donald. Su último libro (Bellah, 2011) detecta un curso evolutivo unitario en el que la visión episódica de la realidad, la narrativa mítica y la abstracción depurada del concepto conforman una familia cultural que producen novedad en lo real y que aboca al hombre contemporáneo a saberse un verso suelto y agente creador en el hecho evolutivo. 
Sobre la base de autores como Donald, Deacon, Tomasello, Joas, Deutery, especialmente, Jung, la investigación social intenta reconstruir teóricamente los puentes entre los polos enfrentados, mito y razón, que ha fomentado la teoría social y la filosofía contemporánea desde aquellos inicios marcados por el espíritu ilustrado que priorizaba el entendimiento humano como único garante del progreso social. Este embrión cultural de los procesos de secularización fractura cualquier vínculo interno entre las pautas culturales de la evolución humana. Sobre estas bases toda definición de creatividad se descompensa, como bien sabía Freud, en favor de la racionalidad desvitalizadora de Prometeo. El desafío científico actual sobre el trance creativo de la vida social consiste en desbordar las posiciones dualistas y reduccionistas que proponen o una cosa o la otra por exclusión y neutralizando una parte significativa de la memoria filogenética. La clave de la indagación sociológica consiste, en palabras de Jung (2009), en que «<con la evolución de la forma de vida humana no se establece un nuevo nivel sobre la base biológica inmutable, sino que se remodela el edificio total $>$ (p. 1). El autor plantea que «el análisis de la evolución de lo específicamente humano debe incluir los planos de integración superiores y no puede limitarse a los "módulos" aislados para las funciones complementarias. Esta percepción del holismo de la diferencia es una parte de la moneda, y la otra, la continuidad evolutiva. Un concepto específicamente humano de la experiencia, la acción y la comunicación simbólica, que puede abarcar la variedad de formaciones culturales históricas, debe ser desarrollado en su referencia interna y constitutiva a la génesis biológica y a la forma de vida de la especie > (Jung, 2009, pp. 1-2). Se trata de articular (1) las formas icónico-episódicas y (2) las correspondencias indexicales forjadas en la reiteración ritual (3) a partir del empleo lúcido del pensamiento simbólico-universal. Dicho de otro modo, cabe pensar la creatividad en términos de una articulación integradora de los contenidos implícitos en las elaboraciones discursivas culturalmente explícitas como forma de orientar las preguntas, los debates y las respuestas de los actores, como pauta para destilar el sentido y el significado del hacer social, como clave para dirigir y corregir colegiadamente los cambios de la sociedad.

Según Jung (2009), por articulación cabe entender «el hecho antropológico básico consistente en que los hombres hacen comprensibles sus cursos vitales para si y para otros al articular las cualidades vividas y los impulsos motores, transformándolos en desarrollos integrados de la acción y en cadenas de símbolos sintácticamente estructurados >> (p. 12). Nada de la herencia cultural queda fuera de la creatividad. Ni la propia deliberación reflexiva como elemento evolutivo que destila y depura los contenidos episódicos e icónicos que viven más próximos al instinto. Sin embargo, en la creatividad rige la contingencia y la posibilidad en detrimento de determinismos y naturalezas. La creatividad articulada es una opción (Jung, 2016, p. 101) que media entre una racionalidad sin anclaje motivacional (Prometeo) y una emoción despojada de referentes discursivos (Eros). Cabe pensar en una civilización sustentada en una articulación lúcida que, al reintegrar creativamente los diferentes recursos culturales de la especie, permita una participación libre y responsable de los actores en la definición de los problemas del mundo. Esta noción de la creatividad mantendría más afinidad con la idea de autonomía tan ligada a la modernidad. En nuestro tiempo esto es imposible por la hegemonía de la creatividad episódica que todo lo convierte en acontecimiento único, en singularidad irrepetible desligada de cualquier otro hecho social y ajena a cualquier voluntad de orientación social. La continuidad perdura en los hilos sutiles de la memoria de la especie. Sin embargo, como es el caso de nuestro actual modelo social, la creatividad no vive como destino la activación de los mecanismos de la teoría y de la articulación. Tampoco sería una anomalía histórica por ello. Ocurre en la mayoría de casos de la historia social en los que, como bien indica Castoriadis (1989), la autonomía se ha dejado en manos de figuras extrasociales que decidían en lugar de los actores sociales y les despojaba de la capacidad de autocorrección. En estos casos, la heteronomía desplazaba a la autonomía. 
Si una de las causas del malestar cultural de nuestro tiempo es el protagonismo excluyente y reductor de una creatividad estetizante integrada fatalmente en el sistema algorítmico al que edulcora afectivamente sin salir de él, una posible vía de exploración para acercar las palabras y las cosas de los episodios creativos es la de dotar de continuidad a la herencia filogenética para, así, rehabilitar facultades y recursos culturales (mito, rito, liturgias, performances, etc.) que, en clave nietzscheana, hemos olvidado que lo son. Si la expresión episódica sensible al fragmento vivido subjetivamente sabe de la representación ritual y de la secuencia narrativa, todo ello en el plano intersubjetivo, y éste de la teoría con su potencial trascendente de (intentar) pensar subjetivamente el misterio profundo de las cosas, la creatividad amplía el arco de estratos y niveles que conviven sincrónicamente en ella. La renovación lúcida de la experiencia sólo es posible si la mirada contemporánea no absolutiza uno de sus perímetros en detrimento del resto al que silencia como si no existiera. Crear, en un sentido integral hoy ausente, supone articular-se (reflexivamente), dirigir lúcidamente un proceso que nos empieza dirigiendo a los actores con unos sentires que afloran y condicionan la mirada, con unas narrativas y representaciones que hacen visible de qué queremos hablar y con especulación coordinada y reveladora que inventa soluciones a la vez que delimita problemas.

No basta la creatividad ad hoc como trazo fragmentado en el todo social. Si no se limita a un mero ejercicio de esteticismo cortoplacista guiado por especialistas del afecto, la creatividad debe dar pasos en los procesos deliberativos correctores de las normas de la sociedad y en las experiencias mí(s)ticas renovadoras de las imágenes del mundo. Si la particularidad personal que siente integra la coordinación interpersonal que consiente y se abre a reimaginación de los límites del mundo donde todo se presiente y se apreanuncia (Bloch, 2005), la creatividad humana afianza la autonomía social y la responsabilidad planetaria ante las consecuencias de las decisiones humanas. Una sociedad necesita reflexividad creativa que coordine los diferentes planos en la que la renovación tiene lugar, no sólo en la innovación tecnológica, también en la transformación política y en la revitalización axiológica.

Si los miembros de la clase creativa crean sin coordinación con la vida política planetaria la sociedad se resiente. Cojea. Y, con ella, la civilización que cursa sin orientación y sin propósito. Es el malestar que también surgió en modelos sociales del pasado que, como en los imperios teocráticos de las religiones universales, quisieron acercar la realidad intramundanamente defectuosa a la perfección metafísica extramundana sin contar con los sentires y los decires de los fieles, o como en los inicios de una modernidad entregada al uso público de la razón (Kant), en la que el entendimiento derribó las alturas metafísicas y acalló la razón práctica de los actores en nombre de la objetividad científica universal e impersonal. Sólo una integración respetuosa del conjunto de la herencia cultural puede ofrecer un contexto de convivencia en el que la creatividad necesita de todos sus recursos culturales para generar bienestar y evitar el malestar de la cultura. Su origen radica en una sociedad que llama a la responsabilidad social pero que merma sus posibilidades creativas en los actores al aceptar éstos soluciones desconectadas de su capacidad narrativa e impuestas por agentes desconocidos y anónimos. Además de Eros y Prometeo, siempre enemistados en la modernidad, tal vez la figura de Hermes, como arquetipo griego mediador entre los dioses y los hombres, pueda representar una creatividad integral con la que la especie humana puede diseñar acuerdos planetarios desde los que enfrentar desafíos que en la actualidad amenazan el futuro inmediato de la especie humana. 


\section{REFERENCIAS}

Alonso, L. E. y Fernández Rodríguez, C. J. (2013). Los discursos del presente. Un análisis de los imaginarios sociales contemporáneos. Madrid: Siglo XXI.

Assmann, J. (2018). Achsenzeit. Eine Archäologie der Moderne. Munich: C.H.Beck.

Bataille, G. (1997). Las lágrimas de Eros. Barcelona: Tusquets.

Bellah, R. N. (2011). Religion in Human Evolution. From the Paleolithic to the Axial Age. Cambridge: Harvard University Press.

Bloch, E. (2005). El principio esperanza (Vol. 1). Madrid: Trotta.

Boltanski, L. y Chiapello, E. (2002). El nuevo espíritu del capitalismo. Madrid: Akal.

Bröckling, U. (2020). Postheroischen Helden. Berlin: Suhrkamp.

Calame, C. (2002). Eros en la Antigua Grecia. Madrid: Akal.

Castoriadis, C. (1983). La institución imaginaria de la sociedad. Barcelona: Tusquets.

Cristiano, J. (2009). Imaginario instituyente y teoría de la sociedad. Revista Española de Sociología, 11, 101-120.

Dalrymple, T. (2017). Sentimentalismo Tóxico. Madrid: Alianza.

Deacon, T. (1997). The Symbolic Species. New York: Norton.

Donald, M. (1991). The Origins of Modern Mind. Cambridge: Harvard University Press.

Durand, G. (2005). Las estructuras antropológicas del imaginario. México: FCE.

Elias, N. (1995). El proceso de la civilización, México: FCE.

Freud, S. (2018). Psicología de las masas. Madrid: Alianza.

Han, B. C. (2017). La agonía del eros. Barcelona: Herder.

Joas, H. (1992). Die Kreativität des Handelns. Berlin: Suhrkamp.

Joas, H. (2017). Kirche als Moral-agentur? Munich: Kösel.

Jung, M. (2009). Der Bewusste Ausdruck. Anthropologie der Artikulation. Berlín: De Gruyter.

Jung, M. (2016). Qualitative Experience and Naturalized Religion: An Inner Tension in Dewey's Thought? En H. Deusser, H. Joas, M. Jung y M. Schlette (eds.), The Varieties of Transcendence (pp. 91-104). New York: Fordham University Press.

Maffesoli, M. (2001). El instante eterno. El retorno de lo trágico en las sociedades posmodernas. Barcelona: Paidós.

Marcuse, H. (1985). Eros y civilización. Barcelona: Planeta-Agostini.

Maslow, A. H. (1983). El hombre autorrealizado. Barcelona: Kairós.

Morozov, E. (2015). La locura del solucionismo tecnológico. Madrid: Katz.

Nachtwey, O. (2017). Decivilization: On Regressive Tendencies in Western Societies. En H. Geiselberger (ed.), The Great Regression (pp. 130-142). Londres: Polity Press.

Reckwitz, A. (2012). Die Erfindung der Kreativität. Berlin: Suhrkamp.

Reckwitz, A. (2019). Das Ende der Illusionen. Berlin: Suhrkamp. 
Ricoeur, P. (1990). Freud: una interpretación de la cultura. México: Siglo XXI.

Rosa, H. (2017). Resonanz. Berlin: Suhrkamp.

Rosa, H. (2019). Unverfügbarkeit. Viena: Residenz Verlag.

Schiller, F. (2018). Cartas sobre la educación estética de la humanidad. Barcelona: Acantilado.

Schutz, A. y Luckmann, T. (1989). The Structures of the Life-World. Illinois: Northwestern University Press.

Tomasello, M. (2003). Los orígenes culturales de la cognición humana. Buenos Aires: Amorrortu.

Weber, M. (1986). El político y el científico. Madrid: Alianza.

Zafra, R. (2017). El entusiasmo. Precariedad y trabajo creativo en la era digital. Barcelona: Anagrama.

\section{NOTA BIOGRÁFICA}

Celso Sánchez Capdequi es Profesor Titular del departamento de Sociología de la Universidad Pública de Navarra. Desde zonas de investigación como la dimensión simbólica de las creencias contemporáneas, el surgimiento de los valores, la vigencia del hecho religioso y las nuevas expresiones de resacralización social, entre otras, es autor de textos como Imaginación y sociedad. Una hermenéutica creativa de la cultura (Tecnos, Madrid, 1999), Las máscaras del dinero. El simbolismo social de la riqueza (Anthropos, Barcelona, 2004) y En los límites de la con-fusión. Miedos, riesgos y urgencias de la sociedad de la información (La Catarata, Madrid, 2010). Ha dirigido la compilación La creatividad social: narrativas de un concepto actual (Centro de Investigaciones Sociológicas, Madrid, 2017) y más recientemente ha coordinado el libro Creatividad: entre transgresión y normalización (La Catarata, Madrid, 2020). Además de otras muchas colaboraciones en revistas nacionales e internacionales, ha sido profesor visitante en universidades como New School for Social Research (New York), Goethe Universität (Franckfort del Meno), La Sorbonne (París), el Instituto de Sociología de la Georg-August-Universität (Gottingen) y la Humboldt Universität (Berlin). 